\title{
Proposals for a trial marriage between primary and secondary health care in one or two districts in Inner London
}

\author{
C J DICKINSON
}

\begin{abstract}
A plea is made for an experiment in unified health care in one or two of the new district health authorities in Inner London. The essence of the proposal is that district health authorities should hold the contracts of independent contractors, that the independence and entitlements of the contractors should be preserved, but that the district health authorities should manage a unified budget. This could bring many potential and actual advantages. Administrative problems would not be insuperable. If the scheme was successful it could be gradually extended; if unsuccessful it could be wound up without serious consequences.
\end{abstract}

Between January 1980 and April 1981 the members of the London Health Planning Consortium Study Group received much evidence about the sad state of primary health care in Inner London, on the basis of which several recommendations have recently been published. ${ }^{1}$ I was privileged to have been a member of the group and have high hopes that our report may be acted on and help to improve things. But any report agreed by some 15 people with different interests and experience can

St Bartholomew's Hospital Medical College, West Smithfield, London EC1A 7BE

C J DICKINSON, DM, professor of medicine represent only the highest common factor (sometimes incorrectly called the lowest common denominator) of opinion. Such a report cannot be too controversial because otherwise its generally agreed solid and sensible suggestions may get overlooked or ditched-the baby may be lost with the bath water.

My purpose in this paper is to propose a limited experiment in unified health care in one or two of the new Inner London districts. Although many of my colleagues on the study group lent their support, and many groups and individuals from whom we heard evidence also approved the proposal, there was not enough general agreement to make it part of our published report. Since I still believe that the experiment could usefully be tried, I shall try to summarise the arguments briefly, in the hope that at the least they may stimulate discussion, and, at the most, persuade the appropriate DHSS authorities to undertake the experiment.

\section{Influence of NHS structure on behaviour}

Through the bitter experiences of their clients, architects and town planners now realise that buildings themselves influence the ways in which people behave. Some estates and modern housing blocks have remained in good order while others have been quickly vandalised. There are good and bad buildings, and there are also good and bad administrative structures. Those who work in hospitals and medical schools know as well as those who work in industry that the particular arrangement of interrelating committees may to a large extent determine who wields what power and influence, how many people are happy and effective in their jobs, and how many are unhappy and disaffected.

The health services of the United Kingdom were reorganised with the creation of the NHS in 1948, and the profession 
became deeply split between general practitioners and hospital doctors, between independent contractors and salaried employees. In 1974 a great opportunity to unify the administrative structure of public-funded health care within the newly designated area health authorities was lost. Unfortunately, although family practitioner committees were originally established by area health authorities, the only link thereafter was the nomination by the area health authority of a minority of members of each family practitioner committee (11 out of 30) and the provision of accommodation, staff, and services. Thus family practitioner committees sprang up fully grown and effectively answerable to no other body, least of all the area health authority. In particular, the funds that family practitioner committees administered to support primary care came direct from the Secretary of State and were virtually independent of those administered by area health authorities to support mainly hospital services.

The possibility of some administrative change bringing the family practitioner committees and area health authorities into a common structure still existed until this year, but with the proposed "re-reorganisation" and with the abolition of area health authorities the correspondence of geographical areas of responsibility will be lost, except in the case of some singledistrict areas. In most parts of London family practitioner committees will look after primary health care in two or three district health authorities. This is a disastrous development because it eliminates the possibility of bringing together and co-ordinating hospital and primary health care services. I shall illustrate the sort of opportunity now being lost by an analogy.

\section{THE 1974 REORGANISATION AND THE TEACHING HOSPITALS}

In my view, the best feature of the 1974 reorganisation was the pitchforking of the teaching hospitals into their local districts. In London this drew attention in an uncomfortable but astringent way to the unsatisfactory location of several large hospitals. But it had the more immediate effect of removing the cushion that protected the teaching hospitals from the hard financial climate outside. In the City and Hackney District, for example, Barts found its expenditure closely scrutinised by the local Hackney community, and it became intolerable for the staff at Barts as well as the community to accept two disparate standards of hospital care within a single district. Integration is not yet complete, but it soon will be. The nurses and medical students at Barts now receive an important part of their training in the local district hospitals in Hackney and Shoreditch, with advantages both to themselves and to the hospitals concerned. Similar integration has occurred in many other districts with teaching hospitals. Few, probably none, of these changes would have taken place on their own: the 1974 reorganisation, especially the financial rearrangements for district funding, brought them about.

\section{The 1981-2 reorganisation and primary health care: a pilot integrated district service}

Suppose that some particular district health authority was given the total responsibility, administrative and financial, for providing all health services, and the family practitioner committee responsibility for that district was hived off and put under the control of the district health authority. What would be the advantages? What would be the disadvantages? What would be the administrative problems in mounting such an experiment, in the first instance in perhaps one or two districts?

\section{ADVANTAGES}

A forum would be created in which it would be possible to debate, resolve, and take effective executive action on important issues that transcend primary/secondary health care divisions, such as:

Hospital/general practitioner drug prescribing (hospitals are trying to transfer their prescribing to general practitioners to "save money"-even though for patients regularly attending hospital, for hospital doctors, and for general practitioners this contravenes DHSS directives, is inefficient, inconvenient, and in the long run costs more)

Emergency care from general practitioners/hospital casualty departments.

Full access by general practitioners to investigative services

Access by general practitioners to hospital beds

Hospital doctors' involvement with health centres and larger group practices

Shared accommodation between hospital and primary health care staff

Deputising services for general practitioners provided by hospitalbased staff

General practitioners' premises within hospitals

Hospital/home deliveries-halfway houses

Shared obstetric care between general practitioners and hospitals

Day care surgery-for instance, for hernias-and its general practitioner implications

Appointment of some salaried general practitioners, perhaps operating from hospitals, with special responsibilities for socially disadvantaged groups

Involvement of hospital staff in the appointment of general practitioners, and of general practitioners in the appointment of hospital consultants

Provision of contraceptive advice on a basis convenient for and acceptable to the community

Joint effort by hospitals, general practitioners, and community medical officers to secure full registration, postnatal care, and immunisation of newborn infants

Epidemiological experiments with master indexes and record linkages

Experiments with nurse practitioners.

\section{DISADVANTAGES AND ADMINISTRATIVE PROBLEMS}

It is easy to make a meal out of the innumerable administrative difficulties, but I am sure these could be overcome. The main problem obviously lies with the strong suspicions which even an experimental scheme might provoke in general practitioners that their unique "independent contractor" status could be threatened. I cannot see why this need be so. The appropriate contracts could be held by the district health authority and primary health care be administered by a subcommittee answerable to it-a district family practitioner committee. This could be supervised and constrained by the medical practices committee to the same extent as existing family practitioner committees.

It has been put to me that a skilled administrator is needed to run a family practitioner committee and deal with service problems, and that some similarly skilled person would be necessary for a district family practitioner committee. For a pilot experiment it would be sensible to employ a senior, experienced, and perhaps even just-retired administrator from a family practitioner committee to run the district family practitioner committee. Obviously for a pilot experiment a few extra supportive staff would be needed; but if the scheme was successful and family practitioner committees were split up throughout Inner London, the number of extra staff needed would be very small indeed.

Certain aspects of general practitioner reimbursement for ancillary staff and premises, and charges made for filling general practitioner prescriptions are "open-ended"-that is, they are not subject to any sort of cash limit, except on a national scale. It could be argued that there would be no point in incorporating an open-ended commitment within a cash-limited district health authority budget. Although I most strongly oppose any individual sanction on general practitioner prescribing, including the use of "approved drug" lists, joint budgeting could apply a useful collective sanction within general practice, as it already 
does within hospitals. This could have the nature of a carrot rather than of a stick-for example, if the total prescribing costs for a district could be kept by the individual efforts of general practitioners and hospital staff down to some agreed figure, the extra money could be made available to finance some otherwise unattainable objective, such as a district-based general practitioner/hospital communications system.

It is also worth pointing out that much of a district health authority budget is open-ended anyway, in the sense that district health authorities have no control over national pay awards, which are now implemented with little or even no extra money being made available.

It would be logical, to achieve a unified district health authority budget, to have added to the district budget for hospital services an appropriate proportion of the national costs of general practitioner prescriptions, ancillary staff, and premises, pro rata for the number of general practitioners working within the designated district health authority area. The district health authority could then administer the whole budget, but should be debarred from depriving any of its independent contractors of their entitlements. Moreover, it and its district family practitioner committee should augment the minimum entitlement when the return in primary care was likely to be improved. For example, a district-based system of computerised records for general practice might prove practicable and useful. A district health authority might consider it worth while to make special arrangements for primary care of its homeless people, thus lifting an uncomfortable and awkward burden off the shoulders of local general practitioners. At present I can see no way in which an existing family practitioner committee could cope with such developments even though it has in well-defined respects an open-ended budget. I can see no way in which a district health authority, funded largely on the basis of its responsibilities to provide hospital care, could be induced to take on additional primary care responsibilities. Innumerable other examples could be given of the possibilities opened up by a unified district health authority budget.

Some have told me that the machinery for primary/hospital co-ordination already exists, and will continue, in the district medical committees. Few of these have worked at all, and in London still fewer have worked well, because the two sides have each jealously guarded their independence, and the committees have had no sanctions available.

It would be illogical not to include other independent contractors in a pilot scheme-that is, dentists, opticians, and pharmacists-but the scale of the problems would be much smaller and should be soluble along the same lines as for general practitioners.

\section{POWER OF PUBLIC AND COLLECTIVE PROFESSIONAL OPINION}

Hospitals would inevitably have the main share of the moneys available within a unified district budget. According to hitherto unpublished figures kindly given me by Dr Brian Jarman, and based on a number of reasonable assumptions, the average costs of health services per head of resident population in Inner London in 1977 were: hospitals (£106); administration $(£ 7)$; community $(£ 11)$; general practitioners $(£ 7)$; pharmaceuticals $(£ 11)$. Therefore general practitioners might fear that they would lose out to the superior political muscle of hospital consultants, and primary care, the Cinderella of the health services, might become even more deprived. The same apprehensions were felt in many district hospitals in 1974 when they were forcibly joined with local teaching hospitals-but, as I have pointed out, the opposite happened. Teaching hospitals felt and acknowledged these pressures and changed their attitudes. I believe that the same would happen within a district health authority with responsibility for every aspect of the health care of its community. Just as the 1974 reorganisation made teaching hospitals acknowledge their district responsibility, so I believe that a district health authority in full control of all branches of health care would make hospitals feel more responsibility for, and more concerned in, primary health care. General practitioners and other independent contractors would have an effective voice in hospital activity and hospital developments. Lay members of the district health authority, representing patients' interests, could feel able to influence, within reasonable limits, all the ways in which health care was provided.

The plea has often been made for experiment in the NHS rather than for recurrent reorganisation on a national scale. I support this plea most strongly. My proposal, if implemented in one or two Inner London districts, need cost very little money. It would not be irrevocable. If the pilot scheme floundered the parent family practitioner committees would still be there, and independent general practitioner and other contracts could be handed back while the old structure was intact. If it was successful it could be extended by slow and careful steps, perhaps leading to the progressive replacement of a few large family practitioner committees by a greater number of small district family practitioner committees, with minimal extra cost.

\section{Reference}

1 London Health Planning Consortium Study Group. Primary health care in Inner London. London: DHSS, 1981.

(Accepted 12 Fune 1981)
A man had a bilateral lumbar sympathectomy some time ago and, as he was warned, it has interfered with ejaculation. What is the mechanism of this dysfunction, and is there any treatment for it?

Ejaculation occurs when the muscles of the ductus deferens and seminal vesicles contract and propel their contents into the urethra. Contraction of these muscles is under the control of the sympathetic outflow from the upper lumbar segments of the cord that pass through the lumbar sympathetic ganglia to the hypogastric plexus. Bilateral removal of the whole of the lumbar sympathetic chain is likely to result in failure of ejaculation, though, as most of these operations are performed in old people, the patients rarely complain. Preservation of the first lumbar ganglion, at least on one side, may prevent failure of ejaculation. ${ }^{1}$ There is no effective treatment, but if the patient is worried about infertility it may be possible to collect semen by artificial stimulation. ' Kinmonth JB, Rob CG, Simeone FA. Vascular surgery. London: Edward Arnold,
1962.
What treatment is advised for a 60-year-old woman with chronic bronchitis and emphysema, for which she has had occasional courses of antibiotics to reduce her production of sputum and prevent severe postbreakfast coughing, which causes her to vomit?

Firstly, it is absolutely essential that she never smokes. Secondly, she should take antibiotics whenever her sputum is purulent. Higher doses than usual of some antibiotics may be required. If post-breakfast coughing still causes her to vomit she should take a hot steamy drink first thing in the morning before breakfast and posture for about 20 minutes lying on either side to clear her chest. It would be helpful if someone could be asked to vibrate the appropriate side of her chest meanwhile. Bronchiectasis may also be present, in which case posture drainage twice daily would be essential. When the purulent sputum is cleared expectoration may nevertheless continue: I know of no way of safely reducing this with certainty, though possibly the trial use of bronchodilatory aerosol, corticosteroid aerosol, and even corticosteroid tablets may be considered 